OPEN ACCESS

Edited by:

Alice Sabatino,

University of Parma, Italy

Reviewed by:

Cassiana Regina de Góes, Universidade Federal de Lavras, Brazil

Francesca Di Mario

University Hospital of Parma, Italy

*Correspondence:

Maria Papaioannou

mpapaioannou@auth.gr orcid.org/0000-0003-3149-6523

TORCID:

Spyridon Graidis orcid.org/0000-0003-0356-850X

Theodosios S. Papavramidis orcid.org/0000-0002-7097-9889

Specialty section:

This article was submitted to Clinical Nutrition,

a section of the journal

Frontiers in Nutrition

Received: 18 November 2020 Accepted: 31 December 2020

Published: 04 March 2021

Citation:

Graidis S, Papavramidis TS and Papaioannou M (2021) Vitamin D and Acute Kidney Injury: A Two-Way

Causality Relation and a Predictive,

Prognostic, and Therapeutic Role of Vitamin D. Front. Nutr. 7:630951.

doi: 10.3389/fnut.2020.630951

\section{Vitamin D and Acute Kidney Injury: A Two-Way Causality Relation and a Predictive, Prognostic, and Therapeutic Role of Vitamin D}

\author{
Spyridon Graidis ${ }^{1 \dagger}$, Theodosios S. Papavramidis ${ }^{2+}$ and Maria Papaioannou ${ }^{1 *}$ \\ 1 Laboratory of Biological Chemistry, Faculty of Health Sciences, School of Medicine, Aristotle University of Thessaloniki, \\ Thessaloniki, Greece, ${ }^{2} 1$ st Propedeutic Department of Surgery, Faculty of Health Sciences, School of Medicine, AHEPA \\ University Hospital, Aristotle University of Thessaloniki, Thessaloniki, Greece
}

Background: Acute kidney injury (AKI) constitutes a multi-factorially caused condition, which significantly affects kidney function and can lead to elevated risk of morbidity and mortality. Given the rising scientific evidence regarding vitamin D's (VitD's) multisystemic role, the connection between AKI and VitD is currently being studied, and the complex relation between them has started to be unraveled.

Methods: A systematic review had been conducted to identify the pathogenetic relation of VitD and $A K I$ and the potential role of VitD as a biomarker and therapeutic-renoprotective factor.

Results: From 792 articles, 74 articles were identified that fulfilled the inclusion criteria. Based on these articles, it has been found that not only can VitD disorders (VitD deficiency or toxicity) cause AKI but, also, AKI can lead to great disruption in the metabolism of VitD. Moreover, it has been found that VitD serves as a novel biomarker for prediction of the risk of developing $A K I$ and for the prognosis of AKI's severity. Finally, animal models showed that VitD can both ameliorate AKI and prevent its onset, suggesting its renoprotective effect.

Conclusion: There is a complex two-way pathogenetic relation between VitD disorders and AKI, while, concomitantly, VitD serves as a potential novel predictive-prognostic biomarker and a treatment agent in AKI therapy.

Keywords: vitamin D, acute kidney injury, pathogenesis, biomarker, prediction, prognosis, therapeutic agent

\section{INTRODUCTION}

Acute kidney injury (AKI), acute kidney failure (AKF), or acute renal failure (ARF) is a multi-factorially caused condition, characterized by sudden and rapid loss of kidney function. Acute kidney injury results in further systemic disorders and is related to elevated morbidity and mortality (1). There are many different definitions for AKI, characterized by different biochemical, physiological, and clinical cutoff points. The most preponderant ones are based on serum creatinine (sCr), glomerular filtration rate (GFR), and urine output (UO). According to the Kidney Disease 
Improving Global Guidelines (KDIGO) Clinical Practice Guidelines for Acute Kidney Injury definition, there are three stages of AKI. Stage 1 includes one of the following: (a) 1.5-1.9 times baseline sCr, (b) $\geq 0.3 \mathrm{mg} / \mathrm{dl}$ increase of baseline $\mathrm{sCr}$, or (c) $<0.5 \mathrm{ml} / \mathrm{kg} / \mathrm{h}$ UO for $6-12 \mathrm{~h}$; Stage 2 includes one of the following: (a) 2-2.9 times baseline sCr or (b) $<0.5 \mathrm{ml} / \mathrm{kg} / \mathrm{h}$ for $\geq 12 \mathrm{~h}$; and Stage 3 includes one of the following: (a) 3 times baseline sCr, (b) $\geq 4.0 \mathrm{mg} / \mathrm{dl}$ increase, (c) initiation of renal replacement therapy (RRT), (d) in patients $<18$ years old, a decrease of eGFR $<35 \mathrm{ml} / \mathrm{min} / 1.73 \mathrm{~m}^{2}$, (e) $<0.3 \mathrm{ml} / \mathrm{kg} / \mathrm{h}$ for $>24 \mathrm{~h}$, or (f) anuria $\geq 12 \mathrm{~h} \mathrm{(2)}$.

The pathophysiology of AKI can be classified into: (1) prerenal azotemia (disruption of kidneys' blood inflow, without cellular or structural damage), (2) intrinsic or intrarenal AKI (direct damage to kidney's structure) due to acute tubular necrosis (ATN), vascular damage, and glomerular damage, (3) interstitial AKI (damage of the interstitial tissue), or (4) postrenal AKI (obstruction of urinary tract) (3). Moreover, AKI can be induced by septic shock, cardiogenic shock, pharmaceutical administration, hepatorenal syndrome, obstructive uropathy, and hypovolemia (4).

Due the necessity to specify the causes and the risk factors inducing AKI, many efforts have been made in order to identify sensitive, specific, and cost-efficient biomarkers, which may contribute to early detection and disease prognosis. In this regard, research has been also focused on the relation between $\mathrm{AKI}$ and vitamin $\mathrm{D}$ (VitD).

Apropos of VitD, it is an important part of the physiological function of various systems. VitD is, mainly, produced in the skin via UV radiation-induced transformation of 7 dehydroxycholesterol (7DHC) to cholecalciferol, which then undergoes consecutive hydroxylations in the liver and kidneys, accordingly, which leads to the synthesis of $1,25(\mathrm{OH})_{2} \mathrm{D}$ $(5,6)$. However, $1,25(\mathrm{OH}) 2 \mathrm{D}$ can be synthesized into many extrarenal tissues, which possess the CYP27B1 enzyme, which is essential for the process (7). VitD's effects are classified into endocrine, paracrine, and autocrine, while the mechanism of action is both genomic [based on the action of VitD receptor (VDR) on VitD response elements (VDREs)] and non-genomic $(8,9)$. Briefly, VitD affects, significantly, calciumphosphate homeostasis, leads to bone reabsorption, enhances muscular contraction and proliferation, intensifies myocardial contracture and lowers blood pressure via affecting the renin-angiotensin-aldosterone system (RAAS), enhances innate immunity and changes the cytokine and chemokine profile of acquired immunity from proinflammatory to antiinflammatory, and protects against autoimmune response and cancer (10).

The aim of the present systematic review is to unravel the relationship between AKI and VitD in both patients and experimental models. We assumed that this is a two-way relationship, insinuating that on the one hand, VitD levels may play a role in AKI, and inversely, AKI induces changes in VitD levels. In this perspective, we examined whether hypoor hypervitaminosis causes AKI and, inversely, whether AKI causes hypo- or hypervitaminosis. It was actually pointless to search for active comparators. Moreover, we examined possible implications of VitD as a predictive and prognostic marker for AKI, as well as its role in AKI treatment.

\section{METHODS}

In May 2020, a bibliographic search was conducted in PubMed, Scopus, and Embase regarding the relation between VitD and AKI. The terms employed were "vitamin D AND AKI," "vitamin D AND ARF," and "vitamin D AND acute kidney injury." Additionally, a manual search of the reference lists of other studies had been conducted, to detect subsequent material that could be included in this systemic review.

Then, the articles were screened, based on:

1. Removing duplicates

2. Relativity to the subject

3. Date of publication

4. Validity of methods and conclusions

Articles that did not meet the above criteria were excluded.

\section{RESULTS}

There were 756 articles identified in the three databases. Moreover, 36 articles have been included from screening the reference lists of the articles. After the exclusion of 336 duplicates and 340 irrelevant studies, the remaining 117 articles were analyzed based on the eligibility for full access and the inclusion criteria. Finally, 74 articles matched our search criteria (Figure 1).

These articles reveal a two-way relation between VitD and AKI. Acute kidney injury can, via various mechanisms, lead to either D hypo- or hypervitaminosis. Moreover, both VitD deficiency and VitD toxicity can lead to the development of AKI.

Given the fact that our knowledge concerning the relationship between VitD and AKI comes from small series, cases, and experimental models, extrapolation of our results to the general population may be risky and biased. Moreover, introducing VitD in the treatment of AKI is also questionable on a clinical basis since there are no prospective randomized trials available and our knowledge is a result of animal experiments. Finally, more clinical data are available on the use of VitD levels as biomarkers concerning both the prediction and the prognosis of AKI. However, despite the fact that there are nine clinical studies on this matter, those studies are observational (either prospective or retrospective), and no data coming from randomized controlled trials are available.

\section{DISCUSSION}

\section{The Development of AKI Is Associated With VitD Disorders}

Acute kidney injury is the significant depletion of renal function, affecting the normal renal enzymatic activity, and consequently disrupts VitD. Usually, the decreased kidney function causes VitD deficiency, but in some cases, VitD toxicity is also observed (Table 1). 


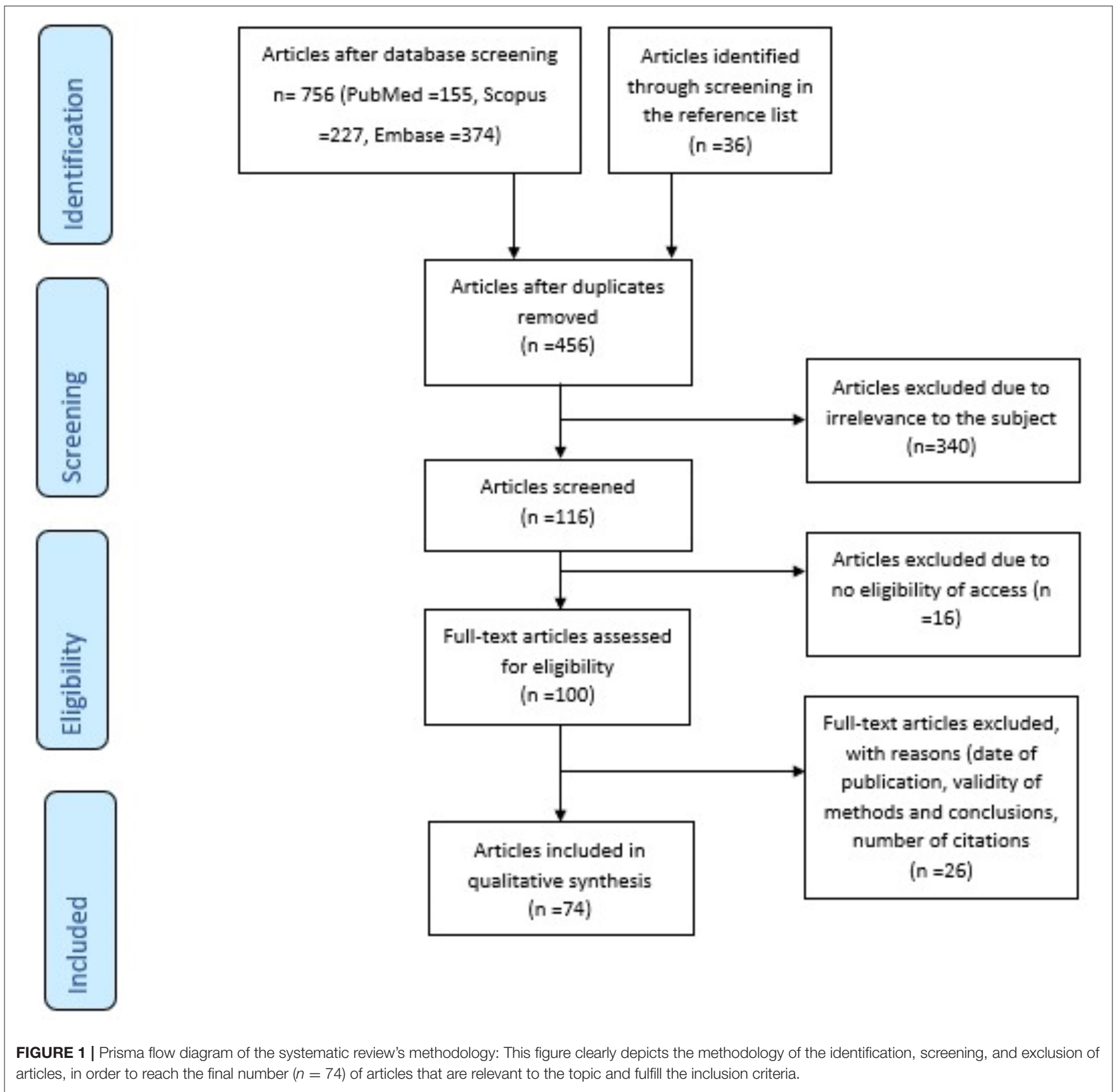

The progressive depletion of renal function during AKI leads to retention and accumulation of phosphate, due to the inability to excrete it. Phosphate acts as a negative regulator of 1-hydroxylase, an enzyme of $1,25(\mathrm{OH})_{2} \mathrm{D}$ synthesis, and therefore negatively contributes to VitD metabolism $(11,12)$. Moreover, as the final hydroxylation takes place in the kidney's active unit, the gradual loss of active nephrons leads to reduced ability of VitD synthesis (11) and to diminution of calcium's intestinal absorption. However, calcium's concentration depletion contributes to an increase of the parathyroid hormone (PTH). Due to secondary hyperparathyroidism and induction of CYP27B1, the levels of VitD can also be elevated $(6,11)$.
Fibroblast growth factor-23 (FGF-23), a phosphaturic factor, induces phosphaturia via acting on FGF-receptor (FGFR)/Klotho coreceptor complex, by (1) downregulating the luminal sodium/phosphate cotransporter in the proximal convoluted tubules, (2) suppressing kidneys' 1-hydroxylase, and (3) inducing 24-hydroxylase, which catalyzes the first step of VitD catabolism, causing hypophosphatemia and significantly lower levels of active VitD $(13,14)$. The soluble Klotho (sKl) can also regulate calcium and phosphate metabolism via an FGF23-independent mechanism affecting the renal outer medullary potassium (ROMK) channel and the transient receptor potential vanilloid-5 (TRPV5). Moreover, sKl has a renoprotective effect 
TABLE 1 | AKI as a cause of vitamin D (VitD) disruptions: AKI leads to the development of either hypovitaminosis $\mathrm{D}$ or hypervitaminosis $\mathrm{D}$ through various mechanisms.

\begin{tabular}{lll}
\hline Condition & Mechanism & Citation \\
\hline Hypovitaminosis D & $\begin{array}{l}\text { Retention and accumulation of phosphate. } \\
\text { Depletion of active nephrons, where the } \\
\text { second hydroxylation occurs. }\end{array}$ & $\begin{array}{c}(11,12) \\
\text { Klotho deficiency leads to secondary } \\
\text { increase of FGF-23 and deterioration of }\end{array}$ \\
& $\begin{array}{l}\text { AKl. } \\
\text { Increase of FGF-23. }\end{array}$ & $(13,14)$ \\
Hypervitaminosis D & $\begin{array}{l}\text { Due to calcium's diminution, the } \\
\text { secondary hyperparathyroidism leads to } \\
\text { induction of CYP27B1. }\end{array}$ & $(6,11)$ \\
& Rhabdomyolysis-induced mechanism.
\end{tabular}

This table presents the mechanisms via which AKI can lead to either VitD deficiency or VitD toxicity. FGF-23, fibroblast growth factor-23; AKI, acute kidney injury; CYP27B1, cytochrome $P 450$ family 27 subfamily $B$ member 1 or $1 \alpha$-hydroxylase.

via (1) the transforming growth factor- $\beta 1$ (TGF- $\beta 1$ )-dependent anti-fibrotic mechanism and (2) the tumor necrosis factor (TNF)/nuclear factor- $\kappa \mathrm{B}(\mathrm{NF} \kappa \mathrm{B})$-dependent anti-inflammatory mechanism (14).

VitD deficiency can be caused by increased expression of FGF23, which has been observed in AKI cases. Leaf et al. presented a case of a 45-year-old male hospitalized due to rhabdomyolysis and with a history of polysubstance abuse. The concurrent AKI was accompanied by elevated levels of FGF-23 and slightly decreased levels of $25(\mathrm{OH}) \mathrm{D}$ and $1,25(\mathrm{OH})_{2} \mathrm{D}(15)$. Additionally, FGF-23 can be secondarily elevated due to Klotho deficiency, which is prevalent, mostly, in chronic kidney disease (CKD) but also has been observed in AKI (13). Klotho's deficiency affects VitD levels, not only by upregulating FGF-23 but also through increasing the extent of AKI, due to depleted renoprotection, and leading, consequently, to greater VitD deficiency (14).

Moreover, Akmal et al. presented a study with patients suffering from rhabdomyolysis and AKI. The patients were initially hypocalcemic. However, during the diuretic phase, an elevation of $25(\mathrm{OH}) \mathrm{D}$ and $1,25(\mathrm{OH})_{2} \mathrm{D}$ was observed, which was greater in patients who developed hypercalcemia (16). These results suggest that the elevation of serum $1,25(\mathrm{OH})_{2} \mathrm{D}$ plays an important role in the development of hypercalcemia and that this increase may be due to extrarenal production or/and dysregulated renal production.

\section{VitD Deficiency Induces AKI}

VitD depletion, VDR knock-out, or disruption of VitD synthesis contributes to AKI development (Table 2) by leading to upregulation of RAAS and to elevated mRNA expression of renal-vascular renin. Due to obstruction and increased levels of extracellular matrix proteins (such as collagen I and fibronectin) and proinflammatory and profibrogenic factors [such as TGF- $\beta$, connective tissue growth factor, and monocyte chemoattractant protein-1 (MCP-1)], the renal injury becomes more severe. Moreover, epithelial-to-mesenchymal transition (EMT) was observed (17). Upon angiotensin I antagonist administration, there was no difference between wild and $\mathrm{VDR}^{-/-}$mice, suggesting that angiotensin II is responsible for the increased renal damage. Contrarily, when VDR agonists were administrated, proteinuria, podocytes' damage, mesangial dilation, macrophage infiltration, oxidative stress damage, proinflammatory and profibrogenic factors, and extracellular matrix protein and neutral lipid accumulation were reduced, proposing that VDR depletion worsens renal injury $(17,18)$.

Moreover, VitD deficiency can exacerbate pre-existing AKI [ischemia/reperfusion injury (IRI) induced AKI] by deteriorating the renal vascular condition and it can accelerate the AKI-toCKD progression, via both an increased TGF- $\beta 1$ signaling and a decreased VDR and Klotho (19-21).

Buttar et al. presented a case of an 86-year-old woman with mild chronic disease and decreased levels of $25(\mathrm{OH}) \mathrm{D}$, who developed rhabdomyolysis and secondary AKI after sitagliptin administration. The patient was on chronic atorvastatin therapy, and a possible interaction between these two drugs is proposed (22).

\section{VitD as a Predictive and Prognostic Biomarker}

In current clinical practice, most assays estimate total $25(\mathrm{OH}) \mathrm{D}$, which cannot distinguish the three different forms of $25(\mathrm{OH}) \mathrm{D}$ [VitD binding protein (VDBP)-bound 25(OH)D, albuminbound $25(\mathrm{OH}) \mathrm{D}$, and free $25(\mathrm{OH}) \mathrm{D}]$. This approach has many limitations since there are many variables that are influenced by physiologic and pathophysiologic conditions. The VDBP's affinity is affected by both hyperlipemic conditions and the three common variants of VDBP's gene, GC1F (group-specific component-1f), GC1S, and GC2 (23). Many efforts were made at inventing new assays that can directly, validly, efficiently, affordably, and quickly estimate free $25(\mathrm{OH}) \mathrm{D}$, rather than calculating it using already-existing multi-factorial formulas. Free $25(\mathrm{OH}) \mathrm{D}$ measurement is considered to have more benefits than total $25(\mathrm{OH}) \mathrm{D}$. So far, the studies have only proved the benefits of free 25(OH)D (1) in cases with differences in VDBP affinity, (2) in the elderly, (3) in pregnancy to detect VitD deficiency, (4) in liver diseases, (5) in kidney disorders (AKI, CKD), (6) in acromegaly, and (7) in allergies associated with atopy and pulmonary function in asthmatic children (23, 24). However, in many studies, no significant superiority of free $25(\mathrm{OH}) \mathrm{D}$ was observed. Still, there were many limitations in some of the studies, due to sample size and due to the use of monoclonal VDBP kits in multiracial/non-Caucasian populations, which affected the outcome $(23,24)$.

Regarding the predictive and prognostic role of VitD and its metabolites, mostly $25(\mathrm{OH}) \mathrm{D}$ but, also, $1,25(\mathrm{OH})_{2} \mathrm{D}$ can act as novel biomarkers of AKI (Supplementary Table 1 ).

Braun et al. found that $25(\mathrm{OH}) \mathrm{D}$ could serve as an independent predictor of AKI since serum 25(OH)D deficiency $(<15 \mathrm{ng} / \mathrm{ml})$ and insufficiency $(15-30 \mathrm{ng} / \mathrm{ml})$ are associated with greater risk of AKI. Moreover, serum $25(\mathrm{OH}) \mathrm{D}$ can also act as independent prognostic biomarker of 30-day mortality since its deficiency and insufficiency are linked to elevated risk of 30-day death (25). 
TABLE 2 | VitD deficiency induces AKI through various mechanisms.

\begin{tabular}{|c|c|c|c|}
\hline Condition & Type of model & Mechanism & Citation \\
\hline \multirow[t]{4}{*}{ VitD deficiency } & Wild-type and VDR ${ }^{-}{ }^{-}$mice & $\begin{array}{l}\text { Upregulation of RAAS via lack of obstruction of angiotensin II receptor and mineral-corticoid } \\
\text { receptor }\end{array}$ & $(17)$ \\
\hline & Diet-induced obesity mice & Elevation of extracellular matrix proteins and of profibrogenic and proinflammatory factors & (18) \\
\hline & Wistar rats & $\begin{array}{l}\text { Deterioration of already-existing renal vascular damage (ischemia/reperfusion injury induced } \\
\text { AKI), which leads to accelerated AKI-to-CKD progression via increased TGF- } \beta 1 \text { signaling and } \\
\text { via decreased VDR and Klotho expression }\end{array}$ & $(19-21)$ \\
\hline & Human case & In rhabdomyolysis-induced AKI, simultaneous administration of atorvastatin and sitagliptin & (22) \\
\hline
\end{tabular}

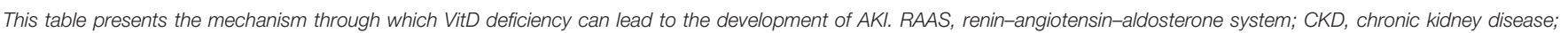
TGF- $\beta 1$, tumor growth factor- $\beta 1$; VDR, VitD receptor.

Similarly, Zapatero et al. showed that serum 25(OH)D can act as a predictor of $A K I$, given that patients with serum $25(\mathrm{OH}) \mathrm{D}<$ $10.9 \mathrm{ng} / \mathrm{ml}$ had greater risk of AKI than VitD-sufficient patients. Moreover, lower levels of serum 25(OH)D were more common in non-survivor patients, and serum $25(\mathrm{OH}) \mathrm{D}$ acted as a prognostic biomarker of mortality (best cutoff value $=10.9 \mathrm{ng} / \mathrm{ml}$ ) $(26)$.

Leaf et al. found by using a two-multivariable-adjustment model that bioavailable $25(\mathrm{OH}) \mathrm{D}$ could serve as an independent prognostic biomarker of sepsis severity $(r=-0.45)$ and mortality, while $25(\mathrm{OH}) \mathrm{D}$ can only correlate with sepsis severity $(r=-0.42)$. Also, VDBP, $1,25(\mathrm{OH})_{2} \mathrm{D}$, and FGF-23 are predictive biomarkers of AKI, while FGF-23 served as biomarker of sepsis severity too $(r=0.35)$ (27).

Sahin et al. found that VitD acts as an independent predictive biomarker of contrast-induced nephropathy (CIN)-AKI, even in multivariable models (28).

Chaykovska et al. found that neither urinary VDBP (uVDBP) nor $\mathrm{uVDBP} / \mathrm{sCr}$ could predict AKI development, but they served as biomarkers of need-of-dialysis, mortality, major adverse renal events (MAREs) (only uVDBP), and non-elective hospitalization. After adjustments, the predictive value of uVDBP was confirmed and was independent of well-known CIN risk factors, such as anemia, already-existing kidney injury, heart failure, and diabetes (29).

Vicente-Vicente et al. found that uVDBP can, potentially, predict the risk of gentamicin-induced AKI, in order to prevent its manifestation, given that increased UVDBP is associated with chronic proclivity to gentamicin nephrotoxicity (30).

Rebholz et al. found that VDBP, free $25(\mathrm{OH}) \mathrm{D}$, bioavailable $25(\mathrm{OH}) \mathrm{D}$, total $25(\mathrm{OH}) \mathrm{D}$, and $1,25(\mathrm{OH})_{2} \mathrm{D}$ (it is the only dependent biomarker) act as independent biomarkers of development of the ESRD stage, even after various multivariable models of adjustments (31).

Lai et al. studied the predictive and prognostic value of $1,25(\mathrm{OH})_{2} \mathrm{D}, 25(\mathrm{OH}) \mathrm{D}$, and $\left[1,25(\mathrm{OH})_{2} \mathrm{D} / 25(\mathrm{OH}) \mathrm{D}\right] \times 1,000$ ratio. As for the prediction of AKI, only $1,25(\mathrm{OH})_{2} \mathrm{D}$ and $\left[1,25(\mathrm{OH})_{2} \mathrm{D} / 25(\mathrm{OH}) \mathrm{D}\right] \times 1,000$ ratio were significant, while as for the prognosis, these two biomarkers had been negatively correlated with AKI stage stratification (Risk, Injury, Failure). None of the markers could predict mortality, while $25(\mathrm{OH}) \mathrm{D}$ showed neither predictive nor prognostic effect (32).

Leaf et al. studied the prognostic value of human cathelicidin antimicrobial protein-18 (hCAP-18), free $25(\mathrm{OH}) \mathrm{D}$ and bioavailable $25(\mathrm{OH}) \mathrm{D}$, and the predictive value of hCAP-18. As for the prognosis, hCAP-18 measured on ICU day 1 is an independent biomarker of sepsis and 90-day mortality, as had been found via univariate and multivariate models of adjustments. However, hCAP-18 showed no significant predictive effect regarding $\mathrm{AKI}$. As for the prognostic value of free and bioavailable $25(\mathrm{OH}) \mathrm{D}$, only the former acted as a biomarker of 90-day mortality, while the latter showed no significant prognostic value (33).

\section{Vitamin D in the Treatment of AKI}

Many studies have been performed mainly with rats to define the potential use of VitD as treatment for AKI (Supplementary Table 2).

A dominant cause of AKI is IRI, induced by the actuation of inflammation and the increased expression of matrix metalloproteinases (MMPs). Ersan et al. studied the effect of paricalcitol on MMPs expression and, subsequently, on IRI progress. Pre-treatment with paricalcitol resulted in amelioration of IRI-AKI via an MMP-dependent inflammatory mechanism (34).

Hamzawy et al. studied the effect of pre-treatment with 22oxacalcitriol (OCT) on IRI-AKI and found that it can ameliorate AKI through: (1) an anti-inflammatory mechanism via inhibition of Toll-like receptor-4 (TLR-4) and interferon- $\gamma$ (IFN- $\gamma$ ), (2) a reduction of $\mathrm{Na}^{+} / \mathrm{H}^{+}$exchanger-1 (NHE-1 exchanger), (3) a pro-autophagic action via elevating Beclin-1 expression and LC3II/LC3I ratio, (4) an anti-apoptotic action via elevating Bax/Bcl-2, cytochrome c and caspase-3 expression, and (5) an inhibitory action on G1 cell cycle arrest via reducing insulin-like growth factor-binding protein-7 (IGFBP-7) and tissue inhibitor of matrix metalloproteinases-2 (TIMP-2) expression (35).

In another study, Kapil et al. also investigated the protective role of VitD pre-treatment in IRI-AKI and showed a renoprotective effect in IRI against oxidation and lipid peroxidation mediated by peroxisome proliferator-activated receptor- $\gamma$ (PPAR- $\gamma)-(36)$.

Additionally, Arfian et al. studied the impact of VitD on IRIAKI and found that its administration can mitigate AKI through reducing the inflammation and the production of myofibroblasts, via reducing the expression TLR-4 and MCP-1 (37).

Also, Silva Barbosa studied the effect of estrogen sulfotransferase (SULT1E1) inhibition on IRI-AKI and found 
that this inhibition attenuates AKI via elevating the VDR activation, as shown by the elevated Cyp24 $\alpha 1$ and Ccnd 1 and by the decreased Fgg expression (38). This effect has been found to be estrogen- and androgen-independent (38). Additionally, only in male mice, the liver expression of Sult1e1 has been found to be necessary for IRI-AKI development, thus proposing a tissueand sex-specific relation between the expression of Sult1e1 and sensitivity to IRI-AKI (38).

Moreover, Lee et al. examined the effect of paracalcitol on IRI and demonstrated that it can attenuate AKI via an antiinflammatory mechanism mediated by the inhibition of TLR- 4 expression and the suppression of NFKB signaling, by increasing I $\mathrm{B}$ in a TNF- $\alpha$-dependent way (39).

$\mathrm{Xu}$ et al. studied the effect of pre-treatment with VitD on liposaccharide (LPS)-induced AKI and found that it can attenuate AKI through: (1) an anti-oxidative mechanism via increasing glutathione (GSH), superoxide dismutase (SOD)-1, and SOD-2 and via decreasing nitric oxide synthase (iNOS), p47phox, and gp91phox (subunits of renal NADPH oxidase) and (2) an anti-apoptotic mechanism (40).

$\mathrm{Du}$ et al. studied the effect of paracalcitol on LPS-AKI and found that its administration ameliorates AKI through: (1) an anti-inflammatory mechanism via reduction of TLR-4 and (2) an anti-apoptotic mechanism via elevation of Bcl-2 (it is antiapoptotic) and via decrease of caspase-3, PUMA (it is a proapoptotic member of the Bcl-2 family), and miR-155 (it targets Bcl-2 and blocks its expression) (41). Regarding the decrease of PUMA and miR-155, it has been found that this is due to the VitD-dependent inhibition of NFKB expression by disrupting the IKK kinase complex or by blocking the p65/p50 nuclear translocation (41).

Park et al. investigated the impact of paricalcitol on cisplatininduced AKI and found that it ameliorated AKI through: (1) inhibiting EMT, (2) reducing apoptosis via increasing Bcl-2 and via decreasing $\mathrm{P}-\mathrm{p} 53$ and $\mathrm{p} 21, \mathrm{p}-\mathrm{Bad}, \mathrm{Bax}$, and caspase- 3 expression, and (3) increasing the cell proliferation via elevating the expression of $\mathrm{p} 27^{\mathrm{kip} 1}$ and decreasing that of cyclin-dependent kinase-2 (CDK2) and Cyclin E. The underlying mechanism of these actions includes the inhibition of TGF- $\beta 1$ and $\mathrm{p} 53$ signaling pathways and the elevation of the p $27^{\mathrm{kip} 1}$ signaling pathway (42).

Another study on the effect of paricalcitol on cisplatininduced AKI demonstrated that the ameliorated AKI was correlated with reduced lipid peroxidation and ferroptotic cell death due to the direct binding of VDR to the glutathione peroxidase 4 (GPX4) promoter, which induces the expression of GPX4, affecting the induction of ferroptosis (43).

Also, Moneim et al. studied the impact of alfacalcidol and BQ123 , a selective endothelin receptor $\mathrm{A}$ blocker $\left(\mathrm{ET}_{\mathrm{A}} \mathrm{R}\right.$ blocker), on cisplatin-induced AKI. Their administration led to attenuation of AKI via a VDR-, ET-1-, and $\mathrm{ET}_{\mathrm{A}} \mathrm{R}$-dependent mechanism, which includes the signaling cascade of Pnf-кBp65, TNF- $\alpha$, and TGF- $\beta 1$. The combined administration of both drugs led to an enhanced therapeutic effect. These results propose a merger of VitD and endothelin-1 signaling pathways, which is promising as a therapeutic option for cisplatin-induced AKI (44).

In another study, administration of $1,25(\mathrm{OH})_{2} \mathrm{D}_{3}$ on gentamicin-induced AKI had no beneficial effect on ameliorating
AKI (45). However, there was a decrease of the systolic blood pressure, to some extent, and an increase of the urine volume, probably due to its inhibitory role in RAAS. Also, VitD acted as an antioxidant factor by increasing GSH (45). So, VitD may be a promising therapeutic agent due to its RAAS- and GSH-related action.

Additionally, El-Boshy et al. studied the role of VitD in paracetamol-induced AKI and liver failure. They found that both the therapeutic and the prophylactic use of VitD can ameliorate $\mathrm{AKI}$ and liver failure through: (1) an anti-apoptotic mechanism via reducing caspase- 3 and (2) a decrease of Cyp24a1 and VDBP expression and an increase of Cyp27b1, Cyp2R1, and VDR expression, (3) an anti-oxidative and anti-inflammatory mechanism via decreasing IL1- $\beta$, IL1R1 (IL-1 receptor 1), IL6 , IL6R (IL-6 receptor), IFN- $\gamma$, IFNGR1 (IFN- $\gamma$ receptor 1), IL17A, and IL17RA (IL-17 receptor A) and via elevating GSH, chloramphenicol acetyltransferase (CAT), Gpx, IL10 (and its gene), IL22, and IL22RA (IL-22 receptor A) (46). The effect of the prophylactic use of VitD has been found to be greater than that of its use for treatment (46).

In another study, the administration of 500 and 1,000 IU/kg VitD can ameliorate AKI and liver failure induced by paracetamol. Interestingly, the dose of $500 \mathrm{IU} / \mathrm{kg}$ presented a greater protective role (47). The underlying mechanism includes: (1) an anti-oxidative action via the reduction of the expression of heme oxygenase 1 (HO-1) and its regulators, $\mathrm{NrF} 2$ and $\mathrm{BACH} 1$, and (2) an anti-inflammatory action via the reduction of NFKB, TNF- $\alpha$, and IL-10 (47).

Finally, Reis et al. studied the impact of calcitriol on rhabdomyolysis-induced AKI and found that AKI was ameliorated through: (1) an anti-inflammatory mechanism via decreasing NFאB and Jun N-terminal kinase (p-JNK), MCP-1, and IL-1 $\beta$, (2) an anti-oxidative mechanism via elevating SOD and via decreasing 8-epi-PGF2 $\alpha$ and nitrotyrosine, (3) reducing vimentin, proliferating cell nuclear antigen (PCNA), and caspase-3, and (4) elevating CYP24 (48).

\section{Vitamin D Toxicity Induced AKI}

Although VitD seems to ameliorate AKI, its administration should be performed with extreme caution. Hypervitaminosis $\mathrm{D}$ can significantly afflict kidney function by inducing hypercalcemia and hyperphosphatemia. Specifically, hypercalcemia leads to the development of nephrogenic diabetes insipidus, which affects water homeostasis by causing polyuria and diuresis. Therefore, there is evident loss of water, leading to hypovolemia, which causes AKI and concomitantly deteriorates the hypercalcemia. So, there is a continuous circle of hypercalcemia causing hypovolemia-induced AKI and vice versa (49-51). Moreover, hypercalcemia and hypercalciuria can lead to deposition of calcium, thus causing nephrolithiasis and renal calcification, which can cause the development of AKI (49-51). Also, hypercalcemia can cause renal vasoconstriction, which subsequently leads to severe GFR decrease and AKI (49-51). As for the hyperphosphatemia, it can cause acute phosphate nephropathy due to the tubulointerstitial deposition of phosphate calcium, a condition that concomitantly worsens the already-existing hyperphosphatemia, thus leading to a 
vicious circle of deterioration (49-51). As for the acute phosphate nephropathy, it can also be due to significant phosphate intake and the subsequent diarrhea-induced hypovolemia (52). Specifically, the hypovolemia leads to great reabsorption of water and sodium chloride in the proximal tubule and the descending limb of Henle's loop, while calcium and phosphate are not that easily reabsorbed (52). As a result, the greater concentration of these substances in the distal tubule and the collecting duct leads to significant deposition of calcium phosphate in these structures, a deposition that is exacerbated due to surface expression of hyaluronan and osteopontin as a result of hypovolemia-induced tubular injury (52). Among risk factors for the development of acute phosphate nephropathy are: advanced age, hypertension, CKD, drugs (such as angiotensin-converting enzyme inhibitors, angiotensin II receptor blockers, and loopor thiazide-type diuretics), female gender, diabetes mellitus, and the use of non-steroidal anti-inflammatory drugs (NSAIDs) (52). As for the treatment of acute phosphate nephropathy, kidney replacement therapy (KRT) can be used to tackle this condition, and particularly, sustained low efficiency dialysis (SLED) has gained ground in treatment, given that it is a hybrid technique, which combines the advantages of both intermittent and continuous KRT (53).

VitD-mediated hypercalcemia can be due to: (1) excessive $\mathrm{VitD}_{2}$ or $\mathrm{D}_{3}$ ingestion/supplementation, (2) extravagant calcitriol ingestion or pharmaceutical administration, (3) elevated ectopic production of calcitriol (evident in granulomatous diseases, such as tuberculosis, sarcoidosis, leprosy, fungal infections, and others; in Hodgkin's and non-Hodgkin's lymphomas; in malignant lymphoproliferative diseases), (4) milk-alkali syndrome (MAS), and (5) depleted catabolism of calcitriol due to mutations of CYP24A1 genes (54).

VitD toxicity due to immoderate administration of VitD supplements or overfortified milk is a global phenomenon (55), potentially affecting kidney function. Chowdry et al. presented a study of VitD toxicity incidents in a tertiary care center at the Sher-i-Kashmir Institute of Medical Sciences, in which 16 out of 19 patients where identified with hypervitaminosis D-induced AKI due to extravagant doses of VitD (median cumulative dose of VitD is 6,000,000 IU), in order to correct VitD deficiency. Not all the patients with toxic levels of $25(\mathrm{OH}) \mathrm{D}$ (>150 ng/ml) developed symptoms (56). Similarly, 13 patients in Brazil developed AKI due to intramuscular injection of veterinary supplements of vitamins $\mathrm{A}, \mathrm{D}$, and $\mathrm{E}$ for esthetic purposes (57).

Also, VitD toxicity-induced AKI has been observed due to anabolic steroid and VitD supplement abuse (58), dispensing errors (59), dosage malpractice and overcorrection of VitD deficiency (60), intramuscular injection of VitD after operation (61), overfortification of milk with VitD (62), over-the-counter supplements (63), and topical treatment with calcitriol analog in combination with oral calcium/VitD for psoriasis (64).

Additionally, in another study, 33 patients with osteoporosis treated with $0.75 \mu \mathrm{g} /$ day eldecalcitol developed hypercalcemiainduced AKI since the discontinuation of eldecalcitol ameliorated the situation (65). Furthermore, 11 patients developed with hypercalcemia-induced AKI, due to alfacalcidol (9 patients) or calcitriol (2 patients) (65).

TABLE 3 | Cases of hypervitaminosis D as cause of AKI.

\begin{tabular}{|c|c|c|c|c|}
\hline References & Article type & Sample size & Substance & Concentration \\
\hline Chowdry et al. (56) & Case series & 19 patients & $25(\mathrm{OH}) \mathrm{D}$ & $371(190-988) \mathrm{ng} / \mathrm{ml}$ \\
\hline Daher et al. (57) & Case series & 16 patients & Vitamin D & $135 \pm 75 \mathrm{ng} / \mathrm{ml}$ \\
\hline Nasri et al. (59) & Case & 1 patient & Vitamin D & $>400 \mathrm{nmol} / \mathrm{L}$ \\
\hline Kaur et al. (60) & Case series & 16 patients & Serum 25(OH)D & $371(175-1,161) \mathrm{ng} / \mathrm{ml}$ \\
\hline Koutkia et al. (63) & Case & 1 patient & Serum 25(OH)D & $487.3 \mathrm{ng} / \mathrm{ml}$ \\
\hline Corden et al. (64) & Case & 1 patient & Vitamin D & N/A \\
\hline Aihara et al. (65) & Case series & 43 patients & $\begin{array}{l}\text { Eldecalcitol ( } 32 \text { patients) } \\
\text { Alfacalcidol ( } 9 \text { patients) } \\
\text { Calcitriol (2 patients) }\end{array}$ & $\mathrm{N} / \mathrm{A}$ \\
\hline Jeong et al. (72) & Case & 1 patient & Calcitriol & $\mathrm{N} / \mathrm{A}$ \\
\hline Asghar et al. (73) & Case & 1 patient & Vitamin D & $119 \mathrm{ng} / \mathrm{ml}$ \\
\hline Tsao et al. (74) & Case & 1 patient & $1,25(\mathrm{OH}) 2 \mathrm{D}_{3}$ & 268 pmol/L \\
\hline
\end{tabular}

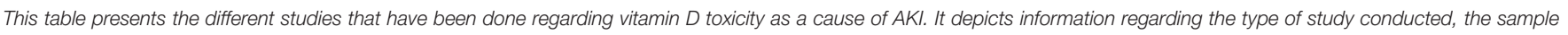
size, the vitamin D-related substance that has been calculated, and the concentration of this substance. 
Moreover, VitD toxicity-induced AKI is related with granulomatous diseases (especially sarcoidosis), MAS, subclinical hyperparathyroidism, and immune reconstitution syndrome.

Tollitt and Solomon presented a case of a 38-year-old male and two other patients with a history of sarcoidosis. After treatment with high doses of cholecalciferol, the patient developed different symptoms of hypercalcemia, such as vomiting, nausea, muscle cramps, and constipation, and subsequent AKI (66). In these cases, the hypercalcemia is due to the extrarenal synthesis of $1,25(\mathrm{OH})_{2} \mathrm{D}$ by macrophages within the sarcoid granulomas, the process of which is without systemic regulation $(67,68)$. The sufficient administration of prednisolone inhibits macrophages' $1-\alpha$ hydroxylase activity and protects against hypercalcemia (66). A similar relation between VitD administration and VitD-induced hypercalcemia has been observed in tuberculosis and Hodgkin's lymphomas $(69,70)$.

MAS is a result of VitD, calcium carbonate, and bisphosphonate administration for osteoporosis, iatrogenic hypothyroidism, and idiopathic hypothyroidism treatment. Although there is limited knowledge regarding its pathophysiology, it affects patients who absorb more calcium than average. Among the risk factors are old age, medication that reduces GFR, and hypovolemia. MAS consists of hypercalcemia, metabolic alkalosis, and renal function disruption, and, particularly, hypercalcemia leads to AKI via renal vasoconstriction, polyuria, and GFR depletion $(71,72)$.

Asghar et al. presented a case of a 55-year-old female who had slightly elevated calcium and was found to be VitD-deficient. The prescription of VitD led later to the development of a giant cystic parathyroid adenoma and to manifestation of parathyroid crisis, accompanied by severe gastrointestinal symptoms and AKI. This suggests that VitD administration can unveil subclinical hyperparathyroidism (73).

Finally, Tsao et al. described a case of immune reconstitution inflammatory syndrome (IRIS) due to Mycobacterium tuberculosis lymphadenitis. It was manifested in a patient with history of silent human immunodeficiency virus-1 (HIV-1) infection, who was in highly active antiretroviral therapy (HAART) because of plasma viral load increase. This 48-year-old male patient, after the initiation of HAART, developed various hypercalcemia symptoms, accompanied by hypervitaminosis $\mathrm{D}\left[1,25(\mathrm{OH})_{2} \mathrm{D}_{3}, 268 \mathrm{pmol} / \mathrm{L}\right]$, which progressed to coma and AKI. IRIS can be due to many opportunistic infections, but the most common infection is $M$. tuberculosis, which is incriminated as the cause of VitD-induced hypercalcemia, which leads to AKI (74). All

\section{REFERENCES}

1. Bellomo R, Ronco C, Kellum JA, Mehta RL, Palevsky P, Workgroup A. Acute renal failure-definition, outcome measures, animal models, fluid therapy and information technology needs: the Second International Consensus Conference of the Acute Dialysis Quality Initiative (ADQI) Group. Crit Care. (2004) 8:R204-12. doi: 10.1186/cc2872 cases of hypervitaminosis D-induced AKI are summarized in Table 3.

\section{CONCLUSION}

It can be concluded that there is a two-way relation between AKI and VitD. Specifically, disruptions of VitD-both hypovitaminosis and hypervitaminosis-can lead to the development of AKI, while also, AKI can contribute to dysregulation of VitD's homeostasis and function.

On this ground, due to this two-way causality relation, VitD is examined on whether its forms can act as a novel biomarker of AKI. Many studies have confirmed VitD's significant role as a predictive (it can help to determine the risk of developing AKI) and prognostic (it can help determine the stage, progress, clinical outcomes, and mortality risk of AKI) biomarker.

Finally, VitD is found to be a potentially important therapeutic factor for AKI due to its multisystemic functions, which include regulation of many enzymic mechanisms via genomic and nongenomic actions.

However, many prospective studies and trials need to be conducted, in order to: (1) fully determine the complex relation between VitD and AKI, (2) find the best cutoff points with the most significant statistic importance, and (3) determine the therapeutic protocols of VitD as treatment of AKI and its potential adverse effects.

Despite the necessity of future studies, VitD is a very promising biomarker and a potential treatment for AKI, which is one the most prominent health problems nowadays.

\section{DATA AVAILABILITY STATEMENT}

The original contributions generated in the study are included in the article/Supplementary Material, further inquiries can be directed to the corresponding author.

\section{AUTHOR CONTRIBUTIONS}

MP and TP: conceptualization and supervision. SG and MP: data curation and investigation. SG: formal analysis and writingoriginal draft. All authors methodology and writing-review and editing.

\section{SUPPLEMENTARY MATERIAL}

The Supplementary Material for this article can be found online at: https://www.frontiersin.org/articles/10.3389/fnut.2020. 630951/full\#supplementary-material 
4. Uchino S, Kellum JA, Bellomo R, Doig GS, Morimatsu H, Morgera S, et al. Acute renal failure in critically ill patients: a multinational, multicenter study. JAMA. (2005) 294:813-8. doi: 10.1001/jama.294.7.813

5. Chen TC, Lu Z, Holick MF. Photobiology of vitamin D. In: Holick MF, editor. Vitamin D. Totowa, NJ: Humana Press (2010). p. 35-60.

6. Schuster I. Cytochromes $\mathrm{P} 450$ are essential players in the vitamin D signaling system. Biochim Biophys Acta Proteins Proteomics. (2011) 1814:186-99. doi: 10.1016/j.bbapap.2010.06.022

7. Zehnder D, Bland R, Williams MC, McNinch RW, Howie AJ, Stewart PM, et al. Extrarenal expression of 25-hydroxyvitamin D 3-1 $\alpha$-hydroxylase 1. J Clin Endocrinol Metab. (2001) 86:888-94. doi: 10.1210/jcem.86. 2.7220

8. Prentice A, Goldberg GR, Schoenmakers I. Vitamin D across the lifecycle: physiology and biomarkers. Am J Clin Nutr. (2008) 88:500S-6S. doi: 10.1093/ajen/88.2.500S

9. Norman AW. From vitamin D to hormone D: fundamentals of the vitamin D endocrine system essential for good health. Am J Clin Nutr. (2008) 88:491S-9S. doi: 10.1093/ajcn/88.2.491S

10. Battault S, Whiting SJ, Peltier SL, Sadrin S, Gerber G, Maixent JM. Vitamin D metabolism, functions and needs: from science to health claims. Eur J Nutr. (2013) 52:429-41. doi: 10.1007/s00394-012-0430-5

11. Audran M, Kumar R. The physiology and pathophysiology of vitamin D. Mayo Clin Proc. (1985) 60:851-66. doi: 10.1016/S0025-6196(12)64791-0

12. Omdahl JL, Morris HA, May BK. Hydroxylase enzymes of the vitamin D pathway: expression, function, and regulation. Annu Rev Nutr. (2002) 22:13966. doi: 10.1146/annurev.nutr.22.120501.150216

13. Wolf M. Forging forward with 10 burning questions on FGF23 in kidney disease. J Am Soc Nephrol. (2010) 21:1427-35. doi: 10.1681/ASN.2009121293

14. Tan S-J, Smith ER, Hewitson TD, Holt SG, Toussaint ND. The importance of klotho in phosphate metabolism and kidney disease. Nephrology. (2014) 19:439-49. doi: 10.1111/nep.12268

15. Leaf DE, Wolf M, Stern L. Elevated FGF-23 in a patient with rhabdomyolysisinduced acute kidney injury. Nephrol Dial Transplant. (2010) 25:1335-7. doi: $10.1093 / \mathrm{ndt} / \mathrm{gfp} 682$

16. Akmal M, Bishop JE, Telfer N, Norman AW, Massry SG. Hypocalcemia and hypercalcemia in patients with rhabdomyolysis with and without acute renal failure. J Clin Endocrinol Metab. (1986) 63:137-42. doi: 10.1210/jcem-63-1-137

17. Zhang Y, Kong J, Deb DK, Chang A, Li YC. Vitamin D receptor attenuates renal fibrosis by suppressing the renin-angiotensin system. J Am Soc Nephrol. (2010) 21:966-73. doi: 10.1681/ASN.2009080872

18. Wang XX, Jiang T, Shen Y, Santamaria H, Solis N, Arbeeny C, et al. Vitamin D receptor agonist doxercalciferol modulates dietary fat-induced renal disease and renal lipid metabolism. Am J Physiol Physiol. (2011) 300:F801-10. doi: 10.1152/ajprenal.00338.2010

19. de Bragança AC, Volpini RA, Mehrotra P, Andrade L, Basile DP. Vitamin D deficiency contributes to vascular damage in sustained ischemic acute kidney injury. Physiol Rep. (2016) 4:e12829. doi: 10.14814/phy2.12829

20. de Bragança AC, Volpini RA, Canale D, Gonçalves JG, Shimizu MHM, Sanches TR, et al. Vitamin D deficiency aggravates ischemic acute kidney injury in rats. Physiol Rep. (2015) 3:e12331. doi: 10.14814/phy2.12331

21. Gonçalves JG, de Bragança AC, Canale D, Shimizu MHM, Sanches TR, Moysés RMA, et al. Vitamin D deficiency aggravates chronic kidney disease progression after ischemic acute kidney injury. PLoS ONE. (2014) 9:e107228. doi: 10.1371/journal.pone. 0107228

22. Buttar RS, Batra J, Kreimerman J, Aleta M, Melamed ML. Rhabdomyolysis and AKI with atorvastatin and sitagliptin use in the setting of low 25-hydroxyvitamin D levels. J Gen Intern Med. (2017) 32:1156-9. doi: 10.1007/s11606-017-4115-x

23. Tsuprykov O, Chen X, Hocher C-F, Skoblo R, Lianghong Yin, Hocher B. Why should we measure free 25(OH) vitamin D? J Steroid Biochem Mol Biol. (2018) 180:87-104. doi: 10.1016/j.jsbmb.2017.11.014

24. Bikle D, Thadhani R, Schoenmakers I. Vitamin D metabolites in captivity? Should we measure free or total $25(\mathrm{OH}) \mathrm{D}$ to assess vitamin D status? J Steroid Biochem Mol Biol. (2017) 173:105-16. doi: 10.1016/j.jsbmb.2017. 01.007

25. Braun $\mathrm{AB}$, Litonjua $\mathrm{AA}$, Moromizato $\mathrm{T}$, Gibbons FK, Giovannucci E, Christopher KB. Association of low serum 25-hydroxyvitamin D levels and acute kidney injury in the critically ill. Crit Care Med. (2012) 40:3170-9. doi: 10.1097/CCM.0b013e318260c928

26. Zapatero A, Dot I, Diaz Y, Gracia MP, Pérez-Terán P, Climent C, et al. La hipovitaminosis $\mathrm{D}$ grave al ingreso en el paciente crítico se asocia a fracaso renal agudo y mal pronóstico. Med Intensiva. (2018) 42:216-24. doi: 10.1016/j.medin.2017.07.004

27. Leaf DE, Waikar SS, Wolf M, Cremers S, Bhan I, Stern L. Dysregulated mineral metabolism in patients with acute kidney injury and risk of adverse outcomes. Clin Endocrinol (Oxf). (2013) 79:491-8. doi: 10.1111/cen.12172

28. Sahin I, Gungor B, Can MM, Avci II, Guler GB, Okuyan E, et al. Lower blood vitamin D levels are associated with an increased incidence of contrastinduced nephropathy in patients undergoing coronary angiography. Can J Cardiol. (2014) 30:428-33. doi: 10.1016/j.cjca.2013.12.029

29. Chaykovska L, Heunisch F, Von Einem G, Alter ML, Hocher C-F, Tsuprykov $\mathrm{O}$, et al. Urinary Vitamin D Binding Protein and KIM-1 Are Potent New Biomarkers of Major Adverse Renal Events in Patients Undergoing Coronary Angiography. (2016). Available online at: http://journals.plos.org/plosone/ article/file?id=10.1371/journal.pone.0145723\&type=printable (accessed August 22, 2018).

30. Vicente-Vicente L, Ferreira L, González-Buitrago JM, López-Hernández FJ, López-Novoa JM, Morales AI. Increased urinary excretion of albumin, hemopexin, transferrin and VDBP correlates with chronic sensitization to gentamicin nephrotoxicity in rats. Toxicology. (2013) 304:83-91. doi: 10.1016/j.tox.2012.12.006

31. Rebholz CM, Grams ME, Lutsey PL, Hoofnagle AN, Misialek JR, Inker LA, et al. Biomarkers of Vitamin D status and risk of ESRD. Am J Kidney Dis. (2016) 67:235-42. doi: 10.1053/j.ajkd.2015.08.026

32. Lai L, Qian J, Yang Y, Xie Q, You H, Zhou Y, et al. Is the serum vitamin D level at the time of hospital-acquired acute kidney injury diagnosis associated with prognosis? PLoS ONE. (2013) 8:e64964. doi: 10.1371/journal.pone.0064964

33. Leaf DE, Croy HE, Abrahams SJ, Raed A, Waikar SS. Cathelicidin antimicrobial protein, vitamin $\mathrm{D}$, and risk of death in critically ill patients. Crit Care. (2015) 19:80. doi: 10.1186/s13054-015-0812-1

34. Ersan S, Celik A, Tanrisev M, Kose I, Cavdar Z, Unlu M, et al. Pretreatment with paricalcitol attenuates level and expression of matrix metalloproteinases in a rat model of renal ischemia-reperfusion injury. Clin Nephrol. (2017) 88:231-8. doi: 10.5414/CN109121

35. Hamzawy M, Gouda SAA, Rashed L, Morcos MA, Shoukry H, Sharawy N. 22-oxacalcitriol prevents acute kidney injury via inhibition of apoptosis and enhancement of autophagy. Clin Exp Nephrol. (2019) 1:43-55. doi: 10.1007/s10157-018-1614-y

36. Kapil A, Singh JP, Kaur T, Singh B, Singh AP. Involvement of peroxisome proliferator-activated receptor gamma in vitamin D-mediated protection against acute kidney injury in rats. J Surg Res. (2013) 185:774-83. doi: 10.1016/j.jss.2013.07.017

37. Arfian N, Budiharjo S, Wibisono DP, Setyaningsih WAW, Romi MM, Saputri RLAANW, et al. Vitamin D ameliorates kidney ischemia reperfusion injury via reduction of inflammation and myofibroblast expansion. Kobe J Med Sci. (2019) 65:E138-43.

38. Silva Barbosa AC, Zhou D, Xie Y, Choi YJ, Tung HC, Chen X, et al. Inhibition of estrogen sulfotransferase (SULT1E1/EST) ameliorates ischemic acute kidney injury in mice. J Am Soc Nephrol. (2020) 31:1496-508. doi: 10.1681/ASN.2019080767

39. Lee J-W, Kim SC, Ko YS, Lee HY, Cho E, Kim M-G, et al. Renoprotective effect of paricalcitol via a modulation of the TLR4-NF- $\mathrm{KB}$ pathway in ischemia/reperfusion-induced acute kidney injury. Biochem Biophys Res Commun. (2014) 444:121-7. doi: 10.1016/j.bbrc.2014.01.005

40. Xu S, Chen Y-H, Tan Z-X, Xie D-D, Zhang C, Xia M-Z, et al. Vitamin D3 pretreatment alleviates renal oxidative stress in lipopolysaccharideinduced acute kidney injury. J Steroid Biochem Mol Biol. (2015) 152:133-41. doi: 10.1016/j.jsbmb.2015.05.009

41. Du J, Jiang S, Hu Z, Tang S, Sun Y, He J, et al. Vitamin D receptor activation protects against lipopolysaccharide-induced acute kidney injury through suppression of tubular cell apoptosis. Am J Physiol Physiol. (2019) 316:F1068-77. doi: 10.1152/ajprenal.00332.2018

42. Park JW, Cho JW, Joo SY, Kim CS, Choi JS, Bae EH, et al. Paricalcitol prevents cisplatin-induced renal injury by suppressing apoptosis and proliferation. Eur J Pharmacol. (2012) 683:301-9. doi: 10.1016/j.ejphar.2012.03.019 
43. Hu Z, Zhang H, Yi B, Yang S, Liu J, Hu J, et al. VDR activation attenuate cisplatin induced AKI by inhibiting ferroptosis. Cell Death Dis. (2020) 11:111. doi: 10.1038/s41419-020-2256-Z

44. Abdel Moneim LM, Helmy MW, El-Abhar HS. Co-targeting of endothelin-A and vitamin D receptors: a novel strategy to ameliorate cisplatin-induced nephrotoxicity. Pharmacol Rep. (2019) 71:917-25. doi: 10.1016/j.pharep.2019.04.018

45. Hur E, Garip A, Camyar A, Ilgun S, Ozisik M, Tuna S, et al. The effects of vitamin d on gentamicin-induced acute kidney injury in experimental rat model. Int J Endocrinol. (2013) 2013:313528. doi: 10.1155/2013/313528

46. El-Boshy M, BaSalamah MA, Ahmad J, Idris S, Mahbub A, Abdelghany $\mathrm{AH}$, et al. Vitamin D protects against oxidative stress, inflammation and hepatorenal damage induced by acute paracetamol toxicity in rat. Free Radic Biol Med. (2019) 141:310-21. doi: 10.1016/j.freeradbiomed.2019.06.030

47. Abo El-Magd NF, Eraky SM. The molecular mechanism underlining the preventive effect of vitamin $\mathrm{D}$ against hepatic and renal acute toxicity through the NrF2/ BACH1/ HO-1 pathway. Life Sci. (2020) 244:117331. doi: $10.1016 /$ j.lfs.2020.117331

48. Reis NG, Francescato HDC, de Almeida LF, Silva CGA da, Costa RS, Coimbra TM. Protective effect of calcitriol on rhabdomyolysis-induced acute kidney injury in rats. Sci Rep. (2019) 9:1-10. doi: 10.1038/s41598-019-43564-1

49. Greenberg A, Cheung AK, Coffman TM, Falk RJ, Jennette JC. Disorders of Calcium and Phosphorus Homeostasis. In: Greenberg A, editor. Primer on Kidney Diseases. Philadelphia, PA: Elsevier (2009). p. 169-79.

50. Deshpandey RP, Kumar HSA, Mathew S. Dyselectrolytemias and acidbase disorder in acute kidney injury. Clin Queries Nephrol. (2012) 1:70-5. doi: 10.1016/S2211-9477(11)70009-7

51. Rocha PN, Santos CS, Avila MO, Neves CL, Bahiense-Oliveira M. Hypercalcemia and acute kidney injury caused by abuse of a parenteral veterinary compound containing vitamins A, D, and E. J Bras Nefrol. (2011) 33:467-71. doi: 10.1590/S0101-28002011000400013

52. Markowitz GS, Perazella MA. Acute phosphate nephropathy. Kidney Int. (2009) 76:1027-34. doi: 10.1038/ki.2009.308

53. Di Mario F, Peyronel F, Greco P, Giunta R, Regolisti G, Fiaccadori E. A case of extreme hyperphosphatemia due to sodium phosphate enemas successfully treated with sustained low efficiency dialysis. Clin Nephrol. (2021) 95:62-4. doi: 10.5414/CN110345

54. Tebben PJ, Singh RJ, Kumar R. Vitamin D-mediated hypercalcemia: mechanisms, diagnosis, and treatment. Endocr Rev. (2016) 37:521-47. doi: 10.1210/er.2016-1070

55. Hilger J, Friedel A, Herr R, Rausch T, Roos F, Wahl DA, et al. A systematic review of vitamin D status in populations worldwide. Br J Nutr. (2014) 111:23-45. doi: 10.1017/S0007114513001840

56. Chowdry AM, Azad H, Saleem Najar M, Mir I. Acute Kidney Injury due to Overcorrection of Hypovitaminosis D: A Tertiary Center Experience in the Kashmir Valley of India. (2017). Available at: http://www.sjkdt.org [accessed August 23, 2018] doi: 10.4103/1319-2442.220873

57. De Francesco Daher E, Mesquita Martiniano LV, Lopes Lima LL, Viana Leite Filho NC, de Oliveira Souza LE, Duarte Fernandes PHP, et al. Acute kidney injury due to excessive and prolonged intramuscular injection of veterinary supplements containing vitamins A, D and E: a series of 16 cases. Nefrología. (2017) 37:61-7. doi: 10.1016/j.nefroe.2016.12.010

58. Daher EF, Silva Júnior GB, Queiroz AL, Ramos LMA, Santos SQ, Barreto DMS, et al. Acute kidney injury due to anabolic steroid and vitamin supplement abuse: report of two cases and a literature review. Int Urol Nephrol. (2009) 41:717-23. doi: 10.1007/s11255-0099571-8

59. Nasri H, Mubarak M. Renal injury due to vitamin D intoxication; a case of dispensing error. J Ren Inj Prev. (2013) 2:85-7. doi: 10.12861/jrip. 2013.27
60. Kaur P, Mishra SK, Mithal A. Vitamin D toxicity resulting from overzealous correction of vitamin D deficiency. Clin Endocrinol (Oxf). (2015) 83:327-31. doi: $10.1111 /$ cen.12836

61. Kumar Bansal R, Tyagi P, Sharma P, Singla V, Arora V, Bansal N, et al. Iatrogenic hypervitaminosis $\mathrm{D}$ as an unusual cause of persistent vomiting: a case report. J Med Case Rep. (2014) 8:74. doi: 10.1186/17521947-8-74

62. Jacobus CH, Holick MF, Shao Q, Chen TC, Holm IA, Kolodny JM, et al. Hypervitaminosis D associated with drinking milk. N Engl J Med. (1992) 326:1173-7. doi: 10.1056/NEJM199204303261801

63. Koutkia P, Chen TC, Holick MF. Vitamin D intoxication associated with an over-the-counter supplement. N Engl J Med. (2001) 345:66-7. doi: 10.1056/NEJM200107053450115

64. Corden E, Higgins E, Smith C. Hypercalcaemia-induced kidney injury caused by the vitamin $\mathrm{D}$ analogue calcitriol for psoriasis: a note of caution when prescribing topical treatment. Clin Exp Dermatol. (2016) 41:899-901. doi: $10.1111 /$ ced.12927

65. Aihara S, Yamada S, Oka H, Kamimura T, Nakano T, Tsuruya K, et al. Hypercalcemia and acute kidney injury induced by eldecalcitol in patients with osteoporosis: a case series of 32 patients at a single facility. Ren Fail. (2019) 41:88-97. doi: 10.1080/0886022X.2019.1578667

66. Tollitt J, Solomon L. Hypercalcaemia and acute kidney injury following administration of vitamin D in granulomatous disease. BMJ Case Rep. (2014) 2014:bcr2014203824. doi: 10.1136/bcr-2014-203824

67. Mason RS, Frankel T, Yuk Luen Chan, Lissner D, Posen S. Vitamin D conversion by sarcoid lymph node homogenate. Ann Intern Med. (1984) 100:59-61. doi: 10.7326/0003-4819-100-1-59

68. Adams JS, Gacad MA. Characterization of 1 alpha-hydroxylation of vitamin D3 sterols by cultured alveolar macrophages from patients with sarcoidosis. $J$ Exp Med. (1985) 161:755-65. doi: 10.1084/jem.161.4.755

69. Lavender TW, Martineau AR, Quinton R, Schwab U. Severe hypercalcaemia following vitamin $\mathrm{D}$ replacement for tuberculosis-associated hypovitaminosis D. Int J Tuberc Lung Dis. (2012) 16:140. doi: 10.5588/ijtld.11.0368

70. Karmali R, Barker S, Hewison M, Fraher L, Katz DR, O’Riordan JLH. Intermittent hypercalcaemia and vitamin D sensitivity in Hodgkin's disease. Postgrad Med J. (1990) 66:757-60. doi: 10.1136/pgmj.66.779.757

71. Altun E, Kaya B, Paydaş S, Balal M. Milk alkali syndrome induced by calcitriol and calcium bicarbonate in a patient with hypoparathyroidism. Indian $J$ Endocrinol Metab. (2013) 17:S191-3. doi: 10.4103/2230-8210.119568

72. Jeong JH, Bae EH. Hypercalcemia associated with acute kidney injury and metabolic alkalosis. Electrolytes Blood Press. (2010) 8:92-4. doi: 10.5049/EBP.2010.8.2.92

73. Asghar A, Islam N. A case report: giant cystic parathyroid adenoma presenting with parathyroid crisis after Vitamin D replacement. BMC Endocr Disord. (2012) 12:14. doi: 10.1186/1472-6823-12-14

74. Tsao Y-T, $\mathrm{Wu} \mathrm{C}-\mathrm{C}$, Chu P. Immune reconstitution syndromeinduced hypercalcemic crisis. Am J Emerg Med. (2011) 29:244.e3-6. doi: 10.1016/j.ajem.2010.03.013

Conflict of Interest: The authors declare that the research was conducted in the absence of any commercial or financial relationships that could be construed as a potential conflict of interest.

Copyright (c) 2021 Graidis, Papavramidis and Papaioannou. This is an open-access article distributed under the terms of the Creative Commons Attribution License (CC $B Y)$. The use, distribution or reproduction in other forums is permitted, provided the original author(s) and the copyright owner(s) are credited and that the original publication in this journal is cited, in accordance with accepted academic practice. No use, distribution or reproduction is permitted which does not comply with these terms. 